\title{
Caracterização farmacognóstica de Polygonum hydropiperoides Michaux e $P$. spectabile (Mart.) (Polygonaceae)
}

\author{
Jácome, R.L.R.P.*1; Lopes, D.E.S. ${ }^{1}$; Recio, R.A. ${ }^{2}$; Macedo, J.F.3; Oliveira A.B. ${ }^{1}$ \\ 'Laboratório de Fitoquímica, Faculdade de Farmácia, Universidade Federal de Minas Gerais; ${ }^{2}$ Fundação \\ Ezequiel Dias (Funed); ${ }^{3}$ Empresa de Pesquisa Agropecuária de Minas Gerais (EPAMIG), \\ Belo Horizonte, MG.
}

RESUMO: Polygonum hydropiperoides e P. spectabile são espécies conhecidas como "ervade-bicho" e utilizadas como antiinflamatórias, anti-hemorroidais e antidiarréicas. As análises farmacognósticas indicaram teores de perda por dessecação, de cinzas totais e de cinzas insolúveis que variaram de 4,0 a 6,5\%; 5,0 a 10,0\% e 0,1 a 0,4\%, respectivamente. Através de cromatografia em camada delgada, foram detectados triterpenos e/ou esteróides, cumarinas, flavonóides, polifenóis, taninos e saponinas nas quatro amostras. Os teores de polifenóis totais, taninos e flavonóides foram de 7,0\%; 5,5\% e 0,4\%, respectivamente, para $P$. spectabile, e diferiram das três amostras de $P$. hydropiperoides, observando-se valores em torno de 5,0\%; 4,0\% e 0,6\% para duas delas e de $12,5 \% ; 11,3 \%$ e $0,3 \%$ para a outra. Estas espécies, morfologicamente muito semelhantes, são empregadas, indiscriminadamente, na produção de medicamentos fitoterápicos. Este estudo mostrou variações nos teores de polifenóis e taninos nas amostras de $P$. hydropiperoides, coletadas no outono e na primavera. Estes resultados representam os primeiros parâmetros obtidos para o controle de qualidade de $P$. hydropiperoides e $P$. spectabile.

Unitermos: Polygonum hydropiperoides; P. spectabile; controle de qualidade.

ABSTRACT: Pharmacognostic characterization of Polygonum hydropiperoides Michaux and P. spectabile (Mart.) (Polygonaceae). Polygonum hydropiperoides and P. spectabile are, commonly known as "erva-de-bicho", and traditionally used as anti-inflammatory, antihaemorrhoidal and anti-diarrhea. The pharmacognostic analysis indicated the content of loss on drying, of total ash and acid-insoluble ash ranged from 4.0 to $6.5 \%, 5.0$ to $10.0 \%$ and 0.1 to $0.4 \%$, respectively. The TLC analysis revealed the presence of triterpenes and/or steroids, coumarins, flavonoids, polyphenols, tannins and saponins in the four samples. The content of total polyphenols, tannins and flavonoids were $7.0 \%, 5.5 \%$ and $0.4 \%$, respectively for $P$. spectabile. They were different from the three samples of $P$. hydropiperoides. The values observed were around $5.0 \%$, $4.0 \%$ and $0.6 \%$ for two of them and $12.5 \%, 11.3 \%$ and $0,3 \%$ for the other one. These species are morphologically very similar and they are used indiscriminately for the production of herbal medicines. This study showed variations on the contents of polyphenols and tannins in samples of $P$. hydropiperoides collected in autumn and spring. These results represent the first parameters obtained for the quality control of $P$. hydropiperoides and $P$. spectabile.

Key words: Polygonum hydropiperoides; P. spectabile; quality control. 


\section{INTRODUÇÃO}

Várias espécies de Polygonum (Polygonaceae) são conhecidas como "erva-de-bicho", a exemplo de P. acre, P. spectabile, P. acuminatum, P. hydropiper e P. hydropiperoides (CORRÊA, 1969; 1978). Este nome popular surgiu do fato de se acreditar serem os mamilos hemorroidários ocasionados por um "bicho" a ser combatido com o decocto dessas plantas (CORRÊA, 1969). Estas espécies são utilizadas internamente como antidiarréicas, anti-hemorroidais, adstringentes (SIMÕES et al., 1986; MARTINS et al., 1995), antissépticas de uso tópico e antidisentéricas (GUPTA, 1995).

Espécies de Polygonum são consideradas como plantas invasoras, pois crescem em muitos sistemas de cultivo utilizados pelo homem, desde áreas agrícolas especialmente úmidas ou sob regime de irrigação, até praças e jardins de centros urbanos. Severamente combatidas, sob pretexto de serem prejudiciais, as plantas invasoras podem, no entanto, ser benéficas quando integram sistemas de manejo de pragas (MACEDO, 1995).

Espécies de Polygonum são muito comercializadas no Brasil, o que deixa claro a necessidade de monografias que estabeleçam parâmetros para o controle de qualidade das espécies utilizadas na fabricação de medicametos fitoterápicos (MUNIZ, 2001).

No presente trabalho, descreve-se a caracterização farmacognóstica de duas espécies: $P$. hydropiperoides e P. spectabile, utilizadas para a fabricação de pomadas, pílulas e supositórios, encontrados no comércio farmacêutico com o nome de Imescard $^{\circledR}$, recomendados para 0 tratamento de hemorróidas.

De espécies de Polygonum já foram isoladas várias substâncias, como por exemplo, flavonóides, sesquiterpenos do tipo drimano, sulfatos de estilbenos e um nor-sesquiterpeno, poligonal (FUKUYAMA et al., 1982; YAGI et al., 1994; XIAO et al., 2000). Também foram isoladas cumarinas e uma isocumarina, identificada como poligonolídeo, para a qual foi atribuída atividade antiinflamatória (FUKUYAMA et al., 1983; FURUTA et al., 1986).

A toxicidade dos extratos etanólico e aquoso de $P$. hydropiperoides foi avaliada em camundongos, nas doses de 250 e $500 \mathrm{mg} / \mathrm{kg}$, por via intraperitoneal, e nenhum dos extratos apresentou sinais de toxicidade nas doses utilizadas (BIANCHI et al., 1993).

O extrato hidroalcóolico a $70 \%$ de $P$. hydropiperoides, contendo flavonóides, taninos e saponinas, apresentou acentuada atividade antiedematogênica em camundongos, nas doses de 250 e $500 \mathrm{mg} / \mathrm{kg}$, por via intraperitoneal. Esses resultados e o amplo uso popular dessa espécie motivaram a avaliação do extrato, por via oral, observando-se uma inibição média do edema de $52 \%$ (OLIVEIRA et al., 1991). Sendo assim, a utilização de $P$. hydropiperoides para o tratamento de hemorróidas parece ter respaldo científico.

\section{MATERIAIS E MÉTODOS}

\section{Material vegetal}

O material vegetal foi coletado em março de 2001, no município de Betim, MG, às margens de um afluente do Rio Paraopeba, segundo as coordenadas geográficas: latitude 1958'02,734"'S e longitude 4915’52,162”W, local este indicado pelo Laboratório Osório de Moraes. A identificação das espécies foi feita pelo biólogo João F. Macedo, da Empresa de Pesquisa Agropecuária de Minas Gerais (EPAMIG). Uma das amostras de P. hydropiperoides (I) e de P. spectabile estavam em lugar sombreado e próximo ao rio, enquanto uma segunda amostra de $P$. hydropiperoides (II), de coloração avermelhada, foi coletada em lugar ensolarado e afastado do rio. Foram coletadas as plantas inteiras (raízes, caules, folhas e flores) e as exsicatas foram depositadas no Herbário PAMG da EPAMIG, e receberam os números 54677 e 54676, respectivamente.

Uma segunda coleta de $P$. hydropiperoides (III) foi feita em novembro de 2001, no município de Nova Serrana, MG, em local ensolarado e alagado. A exsicata também foi depositada no Herbário PAMG, sob o número 55034. 
O material vegetal coletado foi lavado, seco em estufa a $50^{\circ} \mathrm{C}$, durante 2 dias, pulverizado em moinho de facas e o pó grosso (tamis 20) foi armazenado em frascos de vidro.

\section{Análise do material vegetal}

As partes aéreas das amostras coletadas foram analisadas quanto ao seu tamanho, forma e cor, e comparadas com as características botânicas macroscópicas descritas na literatura (CORRÊA, 1969); as observações foram feitas a olho nu.

As determinações de perda por dessecação, de cinzas totais e de cinzas insolúveis foram realizadas segundo metodologias da Farmacopéia Brasileira IV (1996).

\section{Caracterização fitoquímica preliminar}

As classes de metabólitos secundários foram detectadas por cromatografia em camada delgada analítica em gel de sílica G (CCD), para três tipos de extratos: clorofórmio, metanolclorofórmio (1:1) e metanol-água (1:1), preparados a partir do pó das plantas, previamente desengordurado com éter de petróleo. Para detecção da rutina, usou-se como fase móvel acetato de etila:ácido fórmico: ácido acético glacial:água (100:11:11:27) e a placa foi revelada com $\mathrm{AlCl}_{3}$ a $5 \%$ em etanol. Para a detecção de alcalóides terciários e quaternários, o extrato foi preparado por extração ácido-base e a detecção foi feita em tubo de ensaio com reagente de Dragendorff. (MARINIBETOLLO, 1981; WAGNER et al., 1984).

\section{Quantificação espectrofotométrica de polifenóis totais, taninos e flavonóides}

As determinações de polifenóis totais e polifenóis foram realizadas por espectrofotometria no visível usando a reação colorimétrica com ácido fosfotúnsgtico, de acordo com a British Pharmacopeia (1993).

A determinação de flavonóides também foi realizada por espectrofotometria. A técnica se baseia na extração exaustiva do pó com metanol e purificação com clorofórmio através de centrifugação. Uma alíquota da fração metanólica foi adicionada a $0,6 \mathrm{~mL}$ de ácido acético glacial, $10,0 \mathrm{~mL}$ de solução de piridina-água (20:80) e 2,5 mL de solução metanólica de cloreto de alumínio a 6,6 \%. A absorvância da solução foi medida a $420 \mathrm{~nm}$, empregando água como branco. A curva de calibração foi construída a partir das respectivas leituras da absorvância (y) versus as concentrações da rutina $(x \mathrm{mg})$. A equação da reta foi obtida pela curva de calibração e o teor de flavonóides na amostra foi calculado pela inclinação da reta (RUSAK et al., 1993).

\section{Análise estatística}

Os valores foram obtidos a partir da média de três ensaios, realizados para cada uma das amostras coletadas, e foram expressos em porcentagem (\% p/p). O intervalo de confiança para cada média foi calculado pela equação nível de significância de 0,05.

Aplicou-se o teste t de Student com um

\section{RESULTADOS}

Do ponto de vista botânico macroscópico, a amostra de $P$. hydropiperoides (II) apresentavase diferente das demais, com caules e folhas com coloração vermelha, folhas pequenas e em pouca quantidade, caules delgados rastejantes e sem inflorescências terminais. 
Na Tabela 1 estão indicados os valores da perda por dessecação, de cinzas totais e de cinzas insolúveis para as quatro amostras analisadas. Os resultados mostraram que o teor residual de água foi baixo $(<6,5 \%)$. É importante conhecer esse valor, pois ele está relacionado à secagem da droga vegetal e pode ser considerado uma garantia da sua conservação. Os resultados sugerem também que as amostras estavam livres de substâncias aderentes, como terra e areia (FARIAS, 1999; COSTA, 2000).

Tabela 1. Valores obtidos da perda por dessecação, de cinzas totais e de cinzas insolúveis para as amostras de Polygonum spectabile e de P. hydropiperoides analisadas.

\begin{tabular}{|c|c|c|c|}
\hline Amostras & $\begin{array}{c}\text { Perda por } \\
\text { dessecação (\%) }\end{array}$ & Cinzas totais (\%) & Cinzas insolúveis (\%) \\
\hline $\begin{array}{c}\text { P. spectabile } \\
\text { P. hydropiperoides } \\
\text { (I) }\end{array}$ & $5,33 \pm 0,72$ & $9,90 \pm 0,98$ & $0,38 \pm 0,20$ \\
\hline P. hydropiperoides & $5,82 \pm 2,53$ & $7,78 \pm 0,04$ & $0,40 \pm 0,24$ \\
\hline $\begin{array}{c}\text { (II) } \\
\text { P. hydropiperoides } \\
\text { (III) }\end{array}$ & $6,33 \pm 0,70$ & $6,21 \pm 1,14$ & $0,26 \pm 0,18$ \\
\hline
\end{tabular}

Os valores representam a média de três ensaios; $\alpha=0,05$.

\section{Caracterização fitoquímica preliminar}

$\mathrm{Na}$ Tabela 2 estão indicadas as classes de metabólitos secundários presentes nas quatro amostras analisadas, tendo sido detectada a presença de esteróides e/ou triterpenos, cumarinas, flavonóides, polifenóis, taninos e saponinas, em todas elas. A presença da rutina foi detectada apenas em $P$. spectabile, por CCD, em comparação com amostra de referência. A amostra de $P$. hydropiperoides (II) mostrou, em quase todos os sistemas cromatográficos testados, perfis cromatográficos diferentes, enquanto que as outras duas amostras (I e III) sempre apresentaram perfis cromatográficos semelhantes, sugerindo que a amostra II não apresentava boas características para utilização.

Tabela 2. Caracterização fitoquímica preliminar de amostras de Polygonum spectabile e $P$. hydropiperoides.

\begin{tabular}{l|c|c|c|c|}
\multicolumn{1}{|c|}{$\begin{array}{c}\text { Grupos de metabólitos } \\
\text { secundários }\end{array}$} & $\begin{array}{c}P \text {. } \\
\text { spectabile }\end{array}$ & $\begin{array}{c}\text { hydropiperoides } \\
\text { (I) }\end{array}$ & $\begin{array}{c}P . \\
\text { hydropiperoides } \\
\text { (II) }\end{array}$ & $\begin{array}{c}\text { hydropiperoides } \\
\text { (III) }\end{array}$ \\
\hline Esteróides ou Triterpenos & + & + & + & + \\
Cumarinas & + & + & + & + \\
Polifenóis & + & + & + & + \\
Heterosídeos Flavônicos & ++ & ++ & + & ++ \\
Heterosídeos Antracênicos & - & - & - & - \\
Heterosídeos Cardiotônicos & - & - & - & + \\
Saponinas & + & + & + & + \\
Taninos & + & + & + & - \\
Alcalóides terciários & - & - & - & - \\
Alcalóides quaternários & - & - & - & - \\
Rutina & + & - & - & + \\
\hline
\end{tabular}

+ Positivo; ++ Positivo intenso; - Negativo

Rev. Bras. Farmacogn., V. 14, n. 1, jan.-jun. 2004. 


\section{Quantificação espectrofotométrica de polifenóis totais, taninos e flavonóides}

Na Tabela 3 encontram-se os valores obtidos através da quantificação de polifenóis totais, taninos e flavonóides. Pode-se observar que a amostra de $P$. hydropiperoides (II), que foi coletada no outono, em lugar seco e ensolarado, apresentou um teor maior de polifenóis e taninos quando comparada com as três outras amostras, enquanto que o teor de flavonóides foi mais alto para a amostra III que foi coletada na primavera, também em local ensolarado, mas alagado.

Os teores de flavonóides para as três amostras foram calculados usando-se a curva de calibração construída para a rutina. A equação de regressão e o coeficiente de correlação obtidos foram $y=0,0228 x+0,0028\left(R^{2}=0,9992\right)$.

Tabela 3. Quantificação de polifenóis totais, taninos e flavonóides em amostras de Polygonum spectabile e $P$. hydropiperoides.

\begin{tabular}{|c|c|c|c|}
\hline \multirow{2}{*}{ Amostras } & \multicolumn{3}{|c|}{ Teores (\%) } \\
\hline P. spectabile & Polifenóis & Taninos & Flavonóides \\
\hline $\begin{array}{c}7,07 \pm 0,65 \\
\text { P. hydropiperoides } \\
\text { (I) }\end{array}$ & $5,01 \pm 0,50$ & $3,50 \pm 0,77$ & $0,42 \pm 0,19$ \\
\hline $\begin{array}{c}\text { P. hydropiperoides } \\
\text { (II) }\end{array}$ & $12,56 \pm 0,27$ & $11,27 \pm 0,30$ & $0,57 \pm 0,27$ \\
\hline $\begin{array}{c}\text { P. hydropiperoides } \\
\text { (III) }\end{array}$ & $6,50 \pm 1,23$ & $5,30 \pm 1,29$ & $1,03 \pm 0,31 \pm 0,01$ \\
\hline
\end{tabular}

Os valores representam a média de três ensaios; $\alpha=0,05$.

\section{DISCUSSÃO}

Algumas espécies de Polygonum, conhecidas como "erva-de-bicho", são utilizadas para o tratamento de hemorróidas (CORRÊA, 1969). No entanto, somente uma espécie ( $P$. bistorta) consta da Farmacopéia Brasileira (1926), não fazendo parte das outras edições subseqüentes.

Esteróides, triterpenos, cumarinas, flavonóides, polifenóis e saponinas, detectados nas quatro amostras, por CCD, foram isolados de outras espécies de Polygonum (YAGI et al., 1994; FUKUYAMA et al., 1982, 1983, 1985; TSAl et al., 1998). A triagem fitoquímica de $P$. hydropiperoides e $P$. spectabile, realizada por Duarte e colaboradores (1995), indicou a presença de esteróides, polifenóis, taninos condensados, flavonóides, antocianinas, catequinas e saponinas.

A presença de rutina foi comprovada apenas em $P$. spectabile pelas análises em CCD, por comparação com amostra autêntica, resultado semelhante ao obtido anteriormente por Duarte et al. (1995).

Os teores de polifenóis e taninos encontrados para $P$. hydropiperoides I e III variaram de 5,0 a $6,5 \%$ e de 4,0 a 5,3\%, respectivamente, sendo que aqueles encontrados para o espécimem II, de 12,0 e $11,0 \%$, respectivamente, foram superiores aos das outras duas amostras, o que poderia estar relacionado com o estresse ambiental que a mesma sofreu, pois estava em lugar seco, e levando-se em consideração de que esta espécie vegeta em lugares úmidos.

Duarte et al. (1995) relataram teores de polifenóis e taninos para as espécies de $P$. hydropiperoides e $P$. spectabile de $11,73 \%$ e $10,42 \%$ e de $11,33 \%$ e 10,22 , respectivamente. 
Quanto ao teor de flavonóides, a amostra que apresentou maior concentração foi $P$. hydropiperoides (III) coletada na primavera, em ambiente ensolarado e alagado. Pode-se observar um incremento de $80 \%$ do teor de flavonóides na amostra colhida na primavera, em relação à amostra $P$. hydropiperoides (I) colhida no outono. Nas três amostras analisadas inicialmente, no outono, verificou-se que quanto menor o teor de taninos, maior o teor de flavonóides, como observado para o espécimem $P$. hydropiperoides I (Tabela 3). Esta relação é justificada uma vez que flavonas e flavan-3-óis (catequinas) são precursores biossintéticos de proantocianidinas e taninos condensados (COOPER-DRIVE; BHATTACHARYA, 1998).

As amostras de $P$. hydropiperoides II e III, de coloração avermelhadas, coletadas em local ensolarado, apresentaram maiores teores de polifenóis e taninos do que a amostra $P$. hydropipeoides I, coletada em local sombreado.

Para observar a influência da época do ano para a coleta de $P$. hydropiperoides (I e II), foram realizadas comparações dos teores obtidos de polifenóis e taninos, e dos teores de flavonóides entre as amostras coletadas no outono e na primavera. Os resultados obtidos evidenciaram diferenças estatisticamente significantes entre os teores de polifenóis e taninos $(\mathrm{p}<$ $0,015)$ e o de flavonóides ( $p<0,007)$.

Os resultados destas análises mostraram uma variação intraespecífica nos teores de polifenóis, taninos e flavonóides para as amostras de $P$. hydropiperoides coletadas no outono e na primavera.

Os valores apresentados neste trabalho representam os primeiros parâmetros obtidos para o controle de qualidade de $P$. hydropiperoides e P. spectabile.

\section{AGRADECIMENTOS}

Ao Laboratório Osório de Moraes e a Fundação de Amparo a Pesquisa de Minas Gerais (FAPEMIG) pela concessão de bolsa de Mestrado a um dos autores (D. E. S. L.).

\section{REFERÊNCIAS}

BIANCHI, N.R.; SILVA, M.O.; SPIASSI, L.; MACHADO, C.A.; BERGONCI, J.I. Ensaio de toxicidade excessiva e "screening" fitoquímico de plantas usadas popularmente no tratamento de afecções gastro-intestinais. Revista Brasileira de Farmácia, v.74, n.2, p. 50-51, 1993.

BRITISH PHARMACOPEIA. London: Her Majety's Stationery Office, 1993. 1281p.

COOPER-DRIVE, G.A.; BHATTACHARYA, M. Role of phenolics in plant evolution. Phytochemistry, v.49, n.5, p1165-1174, 1998.

CORRÊA, P. Dicionário de Plantas Úteis do Brasil, Rio de Janeiro: Imprensa Nacional, Ministério da Agricultura, 1969. v.2.

CORRÊA, P. Dicionário de Plantas Úteis do Brasil, Rio de Janeiro: Imprensa Nacional, Ministério da Agricultura, 1978. v.5.

COSTA, A. F. Farmacognosia. 3. ed. Lisboa: Fundação Calouste Gulbenkian, 2000. v. 3.

DUARTE, M.G.R; BRANDÃO, M.; SOARES, I.A.; JÁCOME, R.L.R.P.; OLIVEIRA, A.B. Farmacoquímica de plantas daninhas de uso medicinal - I - Estudos farmacoquímicos de espécies de Polygonum: Polygonum hydropiperoides Mich., Polygonum spectabile Mart. e Polygonum acuminatum H.B.K. Daphne: Revista do Herbário PAMG - EPAMIG, v.5, p.59-62, 1995.

FARIAS, R.M. Avaliação da qualidade de matérias-primas vegetais. In: SIMÕES, C.M.O.; SCHENKEL, E.P.; GOSMANN, G.; MELLO, J.C.P.; MENTZ, L.A.; PETROVICK, P.R. (Org.). Farmacognosia: da planta ao medicamento. Florianópolis: Editora da UFSC; Porto Alegre: Editora da UFRGS, 1999.

Rev. Bras. Farmacogn., V. 14, n. 1, jan.-jun. 2004. 
FARMACOPÉIA dos Estados Unidos do Brasil. São Paulo: Companhia Editora Nacional, 1926.

FUKUYAMA, Y.; SATO, T.; ASAKAWA, Y.; TAKEMOTO T. A potent cytotoxic warburganal and related drimanetype sesquiterpenoids from Polygonum hydropiper. Phytochemistry, v. 21, n.12, p. 2895-2898, 1982.

FUKUYAMA, Y.; SATO, T.; MIURA, I.; ASAKAWA, Y.; TAKEMOTO T. Hydropiperoside, a novel coumaryl glycoside from the roots of Polygonum hydropiper. Phytochemistry, v. 22, n.2, p. 549-552, 1983.

FUKUYAMA, Y.; SATO, T.; MIURA, I.; ASAKAWA, Y. Drimane-type sesqui- and norsesquiterpenenoids from Polygonum hydropiper. Phytochemistry, v. 24, p. 1521-1524, 1985.

FURUTA, T.; FUKUYAMA, Y.; ASAKAWA, Y. Polygonolide, a isocoumarin from Polygonum hydropiper prossessing anti-inflammatory activity. Phytochemistry, v. 25, p. 517-520, 1986.

GUPTA, M.P. 270 Plantas medicinais Iberoamericanas. Santafé de Bogotá: Editorial Presencia, 1995.

MACEDO, J.F. Fenologia da floração das plantas invasoras no campus-Pampulha da UFMG. Daphne: Rev. do Herbário PAMG, EPAMIG. v.5, n.4, p. 15-27, 1995.

MARINI-BETOLLO, G.B. Preliminary chemical screening of medicinal plants in field conditions. Boletim da WHO, 1981.19p.

MARTINS, E. R.; CASTRO, D. M.; CASTELLANI, D. C.; DIAS, J. E. Plantas Medicinais. Viçosa: UFV, Imprensa Universitária, 1995.

MUNIZ, C. Palestra proferida no III Simpósio Brasileiro de Farmacognosia, Curitiba, 2001.

OLIVEIRA, C.F.; DIEL, E.E.; HENRIQUES, A.T.; SCHAPOVAL, E.E.S.; ZETTLER, C. Estudo farmacológico do extrato total de Polygonum hydropiperoides Michaux. Cadernos de Farmácia, v.7 (Supl.), p.30-32, 1991.

RUSAK, G; KUSTRAK, D.; MALES, Z.; PLESE, N. The determination of the content of polyphenols in the aerial parts of the species Centaurea rupestris L. and C. fritschii Hayek (Asteraceae). Acta Pharmaceutica, v. 43, p. 121-125, 1993.

SIMÕES, C.M.O.; MENTZ, L.A.; SCHENKEL, E.P.; IRGANG, B.E.; STEHMANN, J.R. Plantas da Medicina Popular no Rio Grande do Sul. Porto Alegre: Editora da UFRGS, 1986. 174p.

TSAI, P.; WANG, J.; CHANG, C.; KUO, S.; CHAO, P.L. Constituents and bioactive principles of Polygonum chinensis. Phytochemistry, v. 49, n. 6, p.1663-1666, 1998.

XIAO, K.; XUAN, L.; XU, Y.; BAI, D. Stilbene glycoside sulfates from Polygonum cuspidatum. Journal of Natural Products, v.63, n.10, p.1373-1376, 2000.

WAGNER, H.; BLAT, S.; ZGAINSKY, E.M. Plant drug analysis. Berlin: Springer, 1984.

YAGI, A.; VENURA, T.; OKAMERA, N.; HARAGUCHI, H.; INOTO, T.; HASHIMOTO, K. Antioxidative sulphated flavonoids in leaves of Polygonum hydropiper. Phytochemistry, v. 35, n. 4, p. 885-888, 1994.

*Autor para correspondência:

Profa. Dra. Rose Lisieux R. Paiva Jácome

Laboratório de Farmacognosia

Faculdade de Farmácia

Universidade Federal de Minas Gerais

Av. Olegário Maciel, 2360

CEP. 30180-112, Belo Horizonte, MG

E-mail: lisieux@dedalus.lcc.ufmg.br 